\title{
EXPOSE TO EVOLVE ESTHETICS-A CASE REPORT OF ALTERED PASSIVE ERUPTION
}

\author{
Dr. Jaishree Tukaram Kshirsagar, Dr. Sangeetha.S \\ Department of Periodontology, \\ Tamilnadu Government Dental College, Chennai, Tamilnadu, India
}

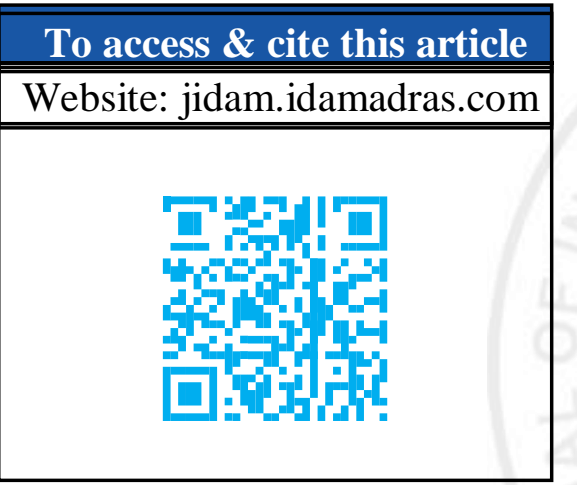

DOI:10.37841/jidam_2020_V7_I3_07

\section{Address for Correspondence:}

\section{Dr. Sangeetha.S.}

Postgraduate Student, Department of

Periodontology,

Tamilnadu Government Dental College,

Muthusamy Salai, George Town

Chennai-600003, Tamilnadu, India

Email id: sangeethadoc1190@gmail com

\section{ABSTRACT}

In dentistry, multidisciplinary approaches are evolved to achieve periodontal esthetics. Dento-gingival relationship increases facial esthetics. The gingival complex is a vital aspect of any restorative treatment plan. "Gummy smile" contributes to esthetic problems and is caused by several factors such as, short upper lip, upper lip hyperactivity, vertical maxillary growth, dentoalveolar extrusion, gingival enlargement, altered passive eruption or a combination. Short clinical crown constitutes gummy smile characterized by displaying gum line during smiling. Esthetic management by periodontal plastic surgical methods is a challenging protocol and it depends on diagnosis and treatment plan. When the gingival tissue fails to recede adequately to level apical to cervical convexity of the crown results in passive eruption of teeth and it is termed as altered passive eruption. This case report entails periodontal management of altered passive eruption which procures esthetic smile.

KEYWORDS: Altered passive eruption, delayed passive eruption, Retarded passive eruption.
Received : $: 15.08 .2020$
Accepted : : 16.09.2020
Published : :27.09.2020 


\section{INTRODUCTION:}

Diagnosis of a smile depends on the amount of gingiva and tooth exposed during smiling. To attain exemplary periodontal esthetics, factors that interfere with the harmony and symmetry of the smile elements must be determined. Excessive gingival appearance exists as an esthetic concern for many patients. This appearance may be caused by skeletal problem, vertical maxillary excess, incomplete exposure of the anatomic crown, dentoalveolar extrusion or combination factors associated with short upper lip or excessive lip translation. Endocrine dysfunctions causing deficiency of growth hormone, epidermal growth factor, insulin like growth factors I and II, hypopituitarism results in delayed dental eruption considering it as etiologic factors for delayed passive eruption ${ }^{1}$. Short clinical crown occurs due to many factors like traumatic injury, incisal attrition, caries [coronal destruction] or tissue hypertrophy or altered passive eruption [coronally situated gingival complex $]^{2}$. If the cause of the gummy appearance is incomplete exposure of the anatomic crown, the teeth will appear unattractive and short.

The first concept of altered passive eruption stated as, when the gingival margin does not migrate to its final position on the cemental surface, instead it remains positioned on or near the enamel surface $^{3}$. 'Altered passive eruption' is defined as failure of the tissue to adequately recede to a level apical to the cervical convexity of the crown ${ }^{4}$. Tissue failure to reach the cementoenamel junction is defined as "delayed passive eruption" 5 and is also known as Retarded passive eruption. Excessive gingival display has been estimated $7 \%$ of men and $14 \%$ of women ${ }^{6}$.

Tooth eruption exits from oral cavity in 2 phases, active and passive eruption ${ }^{7}$. According to the Glossary of Periodontal Terms of the American Academy of Periodontology, Active eruption is "the process by which a tooth moves from its germinative position to its functional position in occlusion with the opposing arch" and Passive eruption is defined as: "tooth exposure secondary to apical migration of the gingival margin" ${ }^{8}$.

Active eruption is the physical movement of tooth from its pre-functional subgingival position through the gingival tissue, into the oral cavity and finally into functional occlusion ${ }^{9}$. Functional active eruption is the continued tooth movement due to wear $^{10}$. Passive eruption is the continued apical movement of the free gingival margin, epithelial attachment or junctional epithelium and connective tissue attachment that occurs after the tooth reaches functional occlusion ${ }^{11}$.

During tooth eruption process, the dentogingival junction shifts apically and it appears when active eruption is completed and may continue until the early or mid-20s of adulthood. At this instance, the free gingival margin approximates the CEJ. Passive eruption was classified into four stages and believed that this was a continuous physiologic process of tooth eruption ${ }^{9}$. Although some debate exists now, when cementum exposure or gingival recession occurs, stage IV of passive eruption can be intended as pathologic process.

Dento-gingival junction was defined into 3 distinct components, gingival sulcus, junctional epithelium, and connective tissue attachment ${ }^{12}$. The dento-gingival junction was later depicted as the "biologic width" by Cohen and depicted as sum of junctional epithelium and connective tissue attachment. Average biologic width is $2.04 \mathrm{~mm}$ and mean sulcular depth was $0.69 \mathrm{~mm}$.

Gargiulo and colleagues [1961] classified and divided passive eruption into four stages:

STAGE I - Gingival sulcus and junctional epithelium are on the enamel [Fig 1a]

STAGE II - Gingival sulcus is on the enamel. 
Junctional epithelium is part on enamel and part on cementum [Fig 1b]

STAGE III - Gingival sulcus is at the cementoenamel junction and junctional epithelium is completely on the cementum [Fig 1c]

STAGE IV - Gingival sulcus and junctional epithelium are apical to cementoenamel junction [Fig 1d]

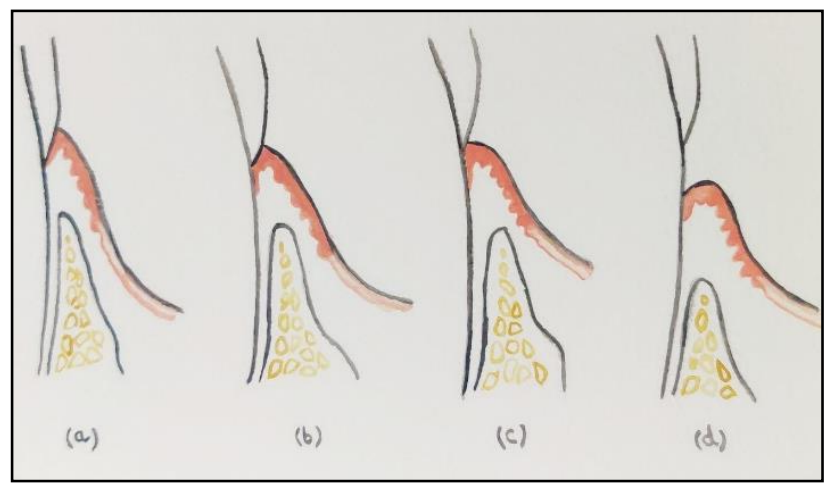

Fig 1: STAGES - Altered passive eruption

\section{ALTERED PASSIVE ERUPTION [Coslet and colleagues 1977] ${ }^{3}$.}

Based on differential diagnosis and treatment

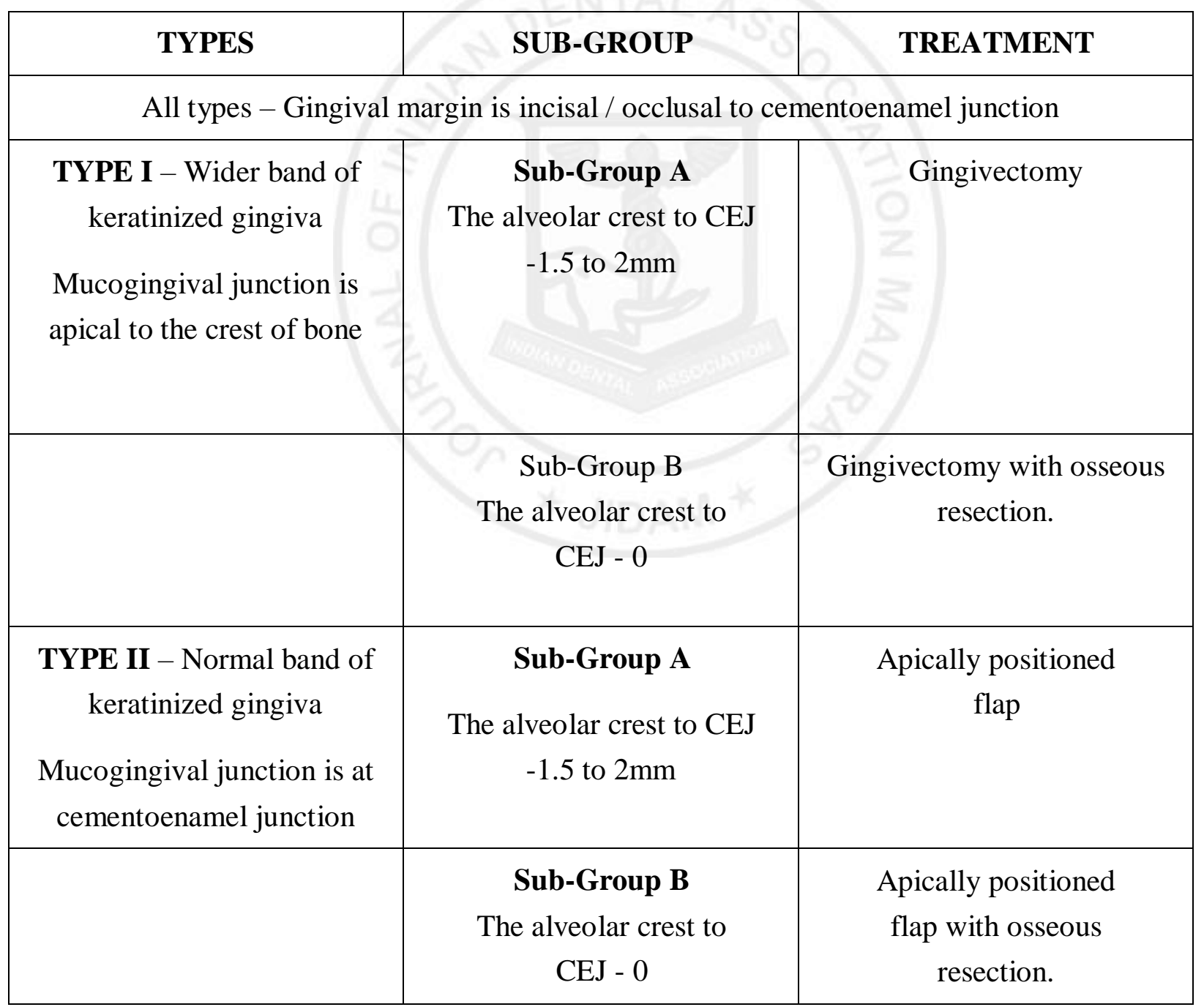




\section{CASE REPORT:}

A 28-year-old female patient reported to the Department of Periodontics with a complaint of excessive gum display and requested for restorative option to improve esthetics. On examination, patient was systematically healthy. On intra-oral examination, patient had no signs of plaque-induced gingival disease. Asymmetric gingival zenith was noted with respect to the lateral incisors of the maxillary arch. The proportions for the clinical crown was determined and radiographic examination revealed the distance of $1.5 \mathrm{~mm}$ between the CEJ and the alveolar crest of the bone. Diagnosis was made as Type I subgroup A APE [Altered passive eruption] and the smile line was examined using Liebert's classification and detected as class 1 . Treatment plan was intricated to the patient and phase I therapy was completed. Written consent was obtained from the patient. Intra- orally, identification of CEJ of individual teeth, the Mucogingival junction and the alveolar crest levels of each tooth were analyzed. Patient was conscious and local anaesthesia was administered to the confined region. Bone sounding was $5 \mathrm{~mm}$ in relation to lateral incisors and gingivectomy of $2 \mathrm{~mm}$ should be made without gingival rebound to the preoperative levels. Sulcus depth was marked with pocket marker. Using no $15 \mathrm{C}$ blade, external bevel incision was placed from tooth \#13 to 23 till the cementoenamel junction. The incision lines ensue the normal gingival scallop with marked attention given to the gingival zenith of each teeth. The incised tissue was detached from the labial surface, which eliminates pseudopockets and clinically crown height was increased. The area was thoroughly irrigated with normal saline. Remaining keratinized gingiva and gingival display was evaluated intra-operatively. Surgical area was covered with periodontal pack [Coe-pak] to reduce discomfort for the patient while consuming food and beverages. Medication was prescribed to the patient, $400 \mathrm{mg}$ ibuprofen twice daily for 5 days as an analgesic to reduce postoperative pain. Follow up visit was done, and the surgical site was healed completely without any pain, discomfort or sensitivity. Same procedure was carried out from \#43 to 33 . The results of the procedure existed constant at 6 months follow up.

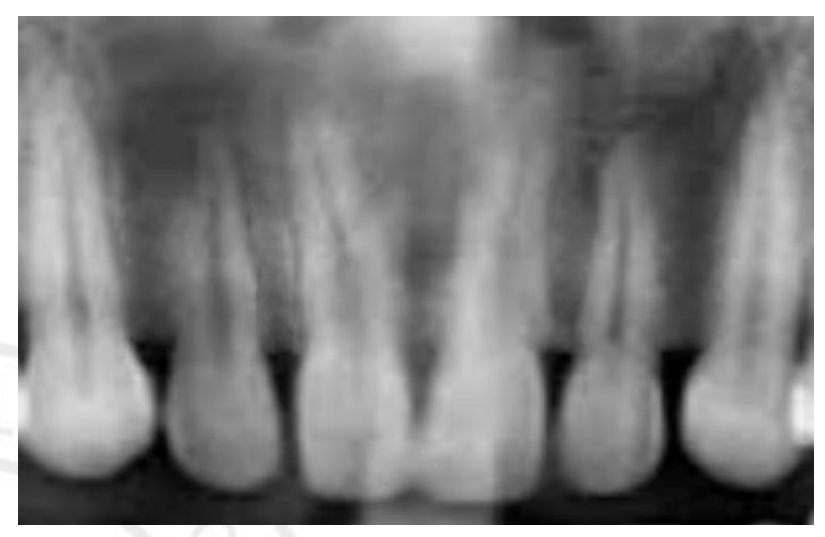

Fig 2: IOPA Pre-operative view

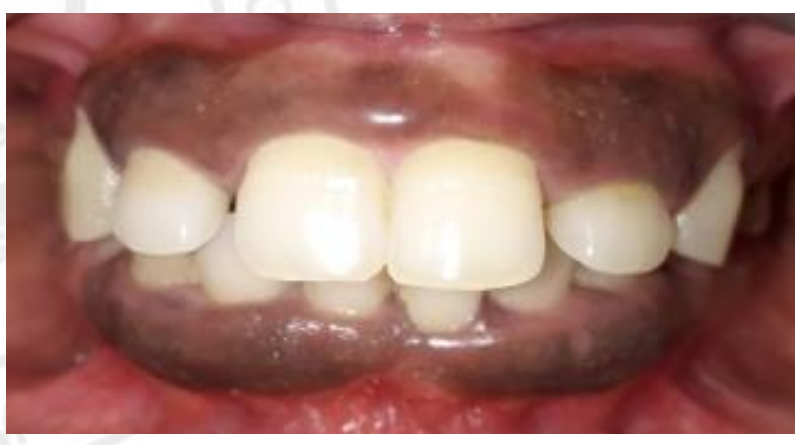

Fig 3: Preoperative view

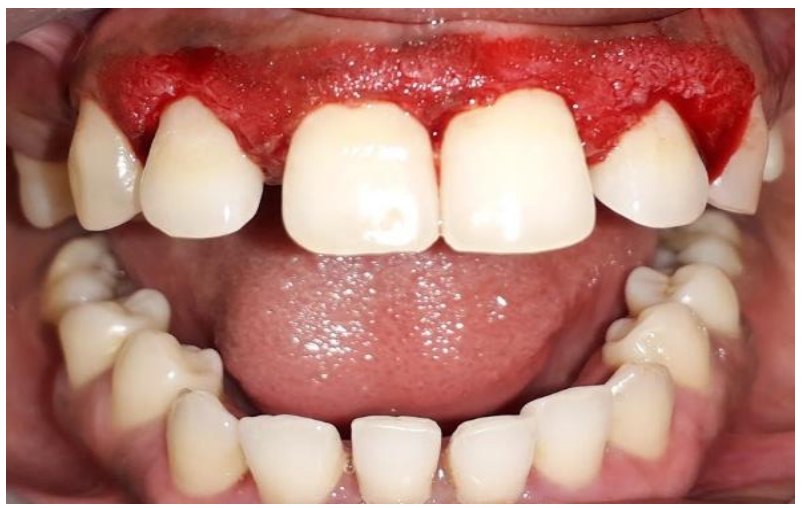

Fig 4: External bevel gingivectomy performed 


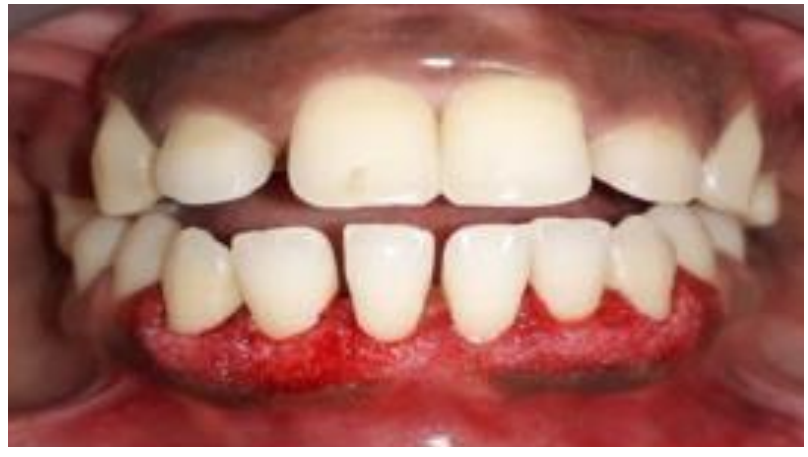

Fig 5: External bevel gingivectomy performed

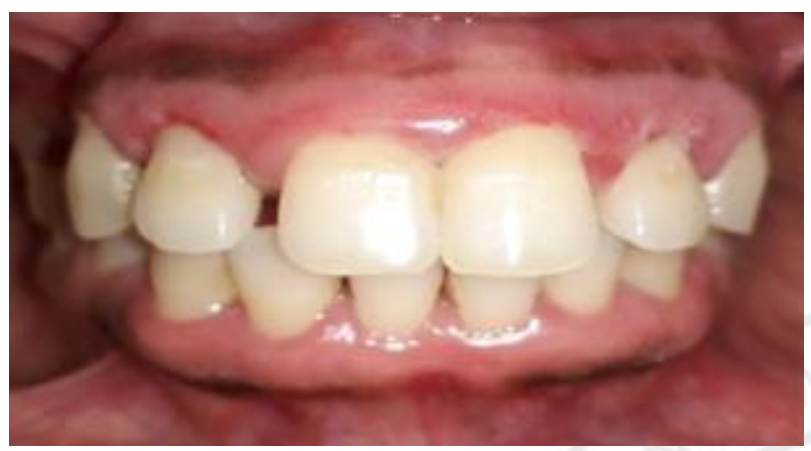

Fig 6: Post-operative view after 1 week

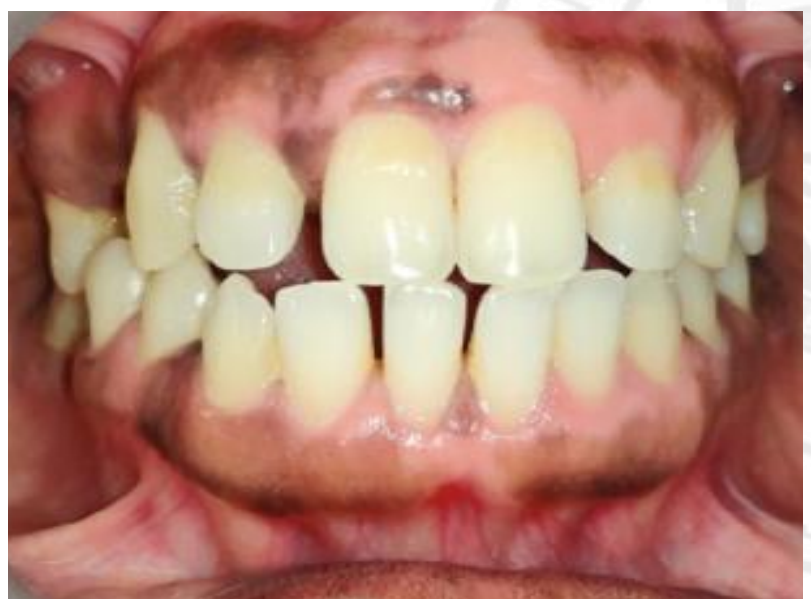

Fig 7: Post-operative view at 6 months

\section{DISCUSSION:}

Gummy smile and short clinical crown are the familiar finding in altered passive eruption. A smile reveals the entire length of the maxillary anteriors, with an incisal curve of the teeth which is parallel to the curvature of the lower lip ${ }^{13}$. Treatment options for altered passive eruption is determined by clinical and radiographic diagnosis. Execution of periodontal surgical procedure depends upon evaluation of gingival architecture, level of crestal bone, gingival biotype, width of keratinized gingiva, position of cementoenamel junction and position of the mucogingival junction. Determination of periodontal biotype is decisive while planning the surgical procedure. Gingival thickness can be appraised with a periodontal probe inserted into the facial aspect of the gingiva sulcus ${ }^{14}$. A flat-thick periodontium implies the presence of dense and fibrotic soft tissue with large amount of keratinized gingiva, thick and flat underlying bone; and a thinscalloped periodontium has thin soft tissue and a small amount of keratinized gingiva with long and narrow papillae over a thin-scalloped bone ${ }^{15}$. These are deliberated to preserve the biological width and any alteration may cause gingivitis, recession, and alveolar bone loss. Extra-orally, lip line of the patient should be detected whether high, medium, or low as it influences the gingival display while smiling ${ }^{16}$. The average length of the maxillary lip in repose is 20 to $22 \mathrm{~mm}$ in females and 22 to $24 \mathrm{~mm}$ in males ${ }^{17}$. If the cause of a gummy smile is maxillary lip, there is no treatment necessary.

\section{CLASSIFICATION OF SMILE LINE (Examined at $30 \mathrm{~cm}$ distance) ${ }^{16}$.}

CLASS $1-\geq 2 \mathrm{~mm}$ of marginal gingiva visible or $\geq$ $2 \mathrm{~mm}$ apical to cementoenamel junction visible for the reduced and healthy periodontium. Referred as gummy smile [Very high smile line]

CLASS 2 - $\leq 2 \mathrm{~mm}$ of marginal gingiva visible or $\leq$ $2 \mathrm{~mm}$ apical to cementoenamel junction visible for the reduced and healthy periodontium [High smile line]

CLASS 3 - Visibility of gingival embrasure only

\section{[Average smile line]}

CLASS 4 - No visibility of gingival embrasure and cementoenamel junction [Low smile line]

Under local anesthesia, alveolar crest is detected by transgingival probing/bone sounding 
through the sulcus to the crest of bone. This procedure provides a method of bone mapping and will supplement diagnostic information. Without following this specific fundamental guidelines, proper diagnosis of APE and maintenance of an ideal biologic width may be difficult to achieve which is integral for long-term esthetics. Detection of CEJ is done with an explorer and the MGJ by roll test. If the CEJ is more apically located or cannot be detected in the sulcus, then a diagnosis of APE can be made. Normally the CEJ lies just apical to gingival margin of the crown. Sulcus depth is usually 2 to $3 \mathrm{~mm}$. In APE, the CEJ might vary from 5 to $10 \mathrm{~mm}$ apical to gingival margin ${ }^{1}$. Thus, altered passive eruption can be rectified by various periodontal surgeries like gingivectomy, gingivoplasty, apically displaced flap with or without osseous resection and undisplaced flap ${ }^{18}$. A mere gingivectomy would be adequate if there is a presence of $2-3 \mathrm{~mm}$ of supracrestal keratinized gingiva after the surgery. Undisplaced flap is performed to contour the alveolar crest margins. Osseous recontouring is indicated when insufficient root is exposed for a proper biologic width.

This case report showed that gingivectomy method of crown lengthening causes no gingival recession or regrowth and stable maintenance of crown length. Treatment of gummy smile is usually based on clinical and radiographic diagnosis and there is no evidence in the periodontal literature with proven statistical analysis and procedures are carried out depending upon classification. Thus, further investigations should be done with large samples in future studies.

Modification of classification was deployed on altered active eruption ${ }^{19}$. Altered active eruption (AAE) is characterized by proximity or coincidence of the alveolar crest to the $\mathrm{CEJ}^{20}$. This modified classification preserves APE Type I and Type II according to the amount of keratinized gingiva, but values were inserted to facilitate a diagnosis (Type $\mathrm{I}:>2 \mathrm{~mm}$ of keratinized tissue; Type II: $\leq 2 \mathrm{~mm}$ ) excluding the subgroups ${ }^{21}$.

\section{CONCLUSION:}

Altered passive eruption was underdiagnosed and not an inevitable pathologic condition. APE is often associated with a short clinical crown and requires surgical approach to correct it. Par for the course, yearned outcomes of periodontal plastic surgery or conjunction with osseous resective surgery in the treatment of altered passive eruption can be successfully achieved through employment of bone sounding and knowledge towards dental soft tissue relationship. Laser surgery has become popular modality now. Modification based on altered active eruption inclusion should be considered. Thus, critical maintenance of biological width and crown lengthening must be attained to abide gingival health.

\section{FINANCIAL SUPPORT AND SPONSERSHIP:}

\section{Nil}

\section{CONFLICTS OF INTEREST:}

There are no conflicts of interest

\section{REFERENCES:}

1. Alpiste-Illueca $\mathrm{F}$ Altered passive eruption (APE): a little-known clinical situation. Med Oral Pathol Oral Cir Bucal 2011; 16(1):100-104.

2. Dolt AH 3rd, Robbins JW. Altered passive eruption: an etiology of short clinical crowns. Quint Int. 1997 Jun;28(6):363-72.

3. Coslet JG, Vanarsdall R, Weisgold A. Diagnosis and classification of delayed passive eruption of the dentogingival junction in the adult. The Alpha Omegan. 1977;70(3):24-28.

4. Goldman HM, Cohen DW. Periodontal Therapy, de 4 St. Louis, C.V. Mosby Company 1968.

5. Volchansky A, Cleaton-Jones PE. Delayed passive eruption. A predisposing factor to Vincent's infection? J Dent Asso S Africa 1974; 29:291-294.

6. Dello Russo NM. Placement of crown margins in patients with altered passive eruption. 
Int J Periodontics Restorative Dent. 1984;4(1):58-65.

7. Weinberg, M. A., \& Eskow, R. N. 2000. An overview of delayed passive eruption. Compendium of Continuing Education in Dentistry (Jamesburg, N.J.: 1995), 21(6), 511- 4, 516, 518 passim; quiz 522.

8. Glossary of Periodontal Terms, The American Academy of Periodontology $4^{\text {th }}$ edition Robert E. Cohen, Chair; Angelo Mariotti; Michael Rethman; and S. Jerome Zackin.

9. Moss-Salentign L, Klyvert M, ed. Dental and oral tissue.3rd ed. Philadelphia: Lea and Febiger; 1990.

10. Gottlieb B, Orban B. Active and passive eruption of teeth. J Dent Res 1933; 13:214.

11. Manson JD (1964). Passive eruption. Dent Pract 14:2-9.

12. Garguilo, orban B. Dimensions and relations of the dentogingival junction in humans. $\mathrm{j}$ periodontal 32, 1961:261-.7.

13. Tjan AHL, Miller GD: The JGP: Some esthetic factors in a smile. J Prosthet Dent 1984; 24-28.

14. Kan JY, Rungcharassaeng K, Umezu K, Kois JC. Dimensions of periimplant mucosa: An evaluation of maxillary anterior single implants in humans. J Periodontol 2003; 74:557-562.

15. De Rouck T, Eghbali R, Collys K, De Bruyn $\mathrm{H}$, Cosyn J. The gingival biotype revisited: Transparency of the periodontal probe through the gingival margin as a method to discriminate thin from thick gingiva. J Clin Periodontol 2009; 36:428-33.

16. Liebert MF, Fouque-Deruelle C, Santini A, Dillier FL, MonnetCorti V, Glise JM, Borghetti A. Smile line and periodontium visibility Period. Prac. Today 2004; 1(1): 17-25.

17. Peck S, Peck L. Esthetics and the treatment of the facial form. Ann Arbor, MI: University of Michigan; 1992. p. 97.

18. Arnett GW, Kreasho RG, Jelic JS. Correcting vertically altered faces: orthodontics and orthognathic surgery. Int J Adult Orthodon Orthognath Surg 1998;13(4):267-76.

19. Mariana S. Ragghianti Zangrando, Giovana

F. Veronesi,Matheus V. Cardoso, Raphaella C. Michel,Carla A. Damante, Adriana C.P. Sant'Ana, Maria L.R. de Rezende, Sebastião L.A. Greghi Altered Active and Passive Eruption: A Modified Classification Clin Adv Periodon, Vol. 7, No. 1, February 2017.

20. Amsterdam MA. Form and Function of the Masticatory System. Philadelphia: University of Pennsylvania; 1991.

21. Lang NP, Loe H. The relationship between the width of keratinized gingiva and gingival health. J Periodontol 1972; 43:623-627. 